\title{
Reviewing innovative Earth Observation solutions for filling science-policy gaps in hydrology
}

Anthony Lehmann ${ }^{\mathrm{a}, \mathrm{b}}$, Gregory Giuliani ${ }^{\mathrm{b}, \mathrm{c}}$, Nicolas Ray ${ }^{\mathrm{b}, \mathrm{c}}$, Kazi Rahman ${ }^{\mathrm{a}, \mathrm{b}}$, Karim C. Abbaspour ${ }^{\mathrm{d}}$, Stefano Nativi ${ }^{\mathrm{e}}$, Massimo Craglia ${ }^{\mathrm{f}}$, Douglas Cripe ${ }^{\mathrm{g}}$, Philippe Quevauviller $^{\mathrm{h}}$, Martin Beniston ${ }^{\mathrm{b}}$

a University of Geneva, Forel Institut, Battelle - Building D, 7 route de Drize, CH-1227 Carouge, Switzerland. Anthony.Lehmann@unige.ch b University of Geneva, Institute for Environmental Sciences, Carouge, Switzerland. c United Nations Environment Programme, Global Resource Information Database - Geneva, Châtelaine, Switzerland.

d Eawag, Swiss Federal Institute of Aquatic Science and Technology, Duebendorf, Switzerland e Italian National Research Council (CNR-IIA), Florence, Italy f European Commission, Joint Research Centre, TP262, Via Fermi, Ispra 21027 (VA), Italy g Group on Earth Observation secretariat, Avenue de la Paix, 7Bis, CP2300, 1211 Geneva 2, Switzerland

h Vrije Universiteit Brussel, Faculty of Engineering, Department of Hydrology and Hydraulic Engineering, Pleinlaan 2, 1050 Brussels, Belgium

\section{Correpsonding author:}

Anthony Lehmann, University of Geneva, enviroSPACE Lab., Battelle - Building D, 7 route de Drize, CH-1227 Carouge, Switzerland. Anthony.Lehmann@unige.ch, + 41763917765

\section{Summary}

Improved data sharing is needed for hydrological modeling and water management that require better integration of data, information and models. Technological advances in Earth observation and Web technologies have allowed the development of Spatial Data Infrastructures (SDIs) for improved data sharing at various scales. International initiatives catalyze data sharing by promoting interoperability standards to maximize the use of data and by supporting easy access to and utilization of geospatial data. A series of recent European projects are contributing to the promotion of innovative Earth observation solutions and the uptake of scientific outcomes in policy. Several success stories involving different hydrologists' communities can be reported around the World.

Gaps still exist in hydrological, agricultural, meteorological and climatological data

This document is the accepted manuscript version of the following article:

Lehmann, A., Giuliani, G., Ray, N., Rahman, K., Abbaspour, K., Nativi, S., ... Beniston, M. (2014).

Reviewing innovative Earth observation solutions for filling science-policy gaps in hydrology.

Journal of Hydrology, 518, 267-277. https://doi.org/10.1016/j.jhydrol.2014.05.059 
access because of various issues. While many sources of data exists at all scales it remains difficult and time-consuming to assemble hydrological information for most projects. Furthermore, data and sharing formats remain very heterogeneous. Improvements require implementing/endorsing some commonly agreed standards and documenting data with adequate metadata. The brokering approach allows binding heterogeneous resources published by different data providers and adapting them to tools and interfaces commonly used by consumers of these resources.

The challenge is to provide decision-makers with reliable information, based on integrated data and tools derived from both Earth observations and scientific models. Successful SDIs rely therefore on various aspects: a shared vision between all participants, necessity to solve a common problem, adequate data policies, incentives, and sufficient resources. New data streams from remote sensing or crowd sourcing are also producing valuable information to improve our understanding of the water cycle, while field sensors are developing rapidly and becoming less costly. More recent data standards are enhancing interoperability between hydrology and other scientific disciplines, while solutions exist to communicate uncertainty of data and models, which is an essential pre-requisite for decision-making. Distributed computing infrastructures can handle complex and large hydrological data and models, while Web Processing Services bring the flexibility to develop and execute simple to complex workflows over the Internet. The need for capacity building at human, infrastructure and institutional levels is also a major driver for reinforcing the commitment to SDI concepts.

\section{Highlights}

- We review the use of Spatial Data Infrastructure in hydrology 
- We identify data gaps between science and policy

- We explore new solutions to bring hydrological modeling closer to policy makers

\section{Keywords}

Hydrological modeling, climate change, data sharing, interoperability, data processing, decision making

\section{Data sharing in hydrology}

Water is a fundamental natural resource and is critical for the well-being of individuals (e.g. health, ecology, economic development) (WWAP 2012). However, shifts in balance between an ever-increasing demand and dwindling supply of water has resulted in new competitive pressures, and also has had a negative influence on water quality (Lecca et al., 2011). Effective and efficient water management requires coordination of actions, one of them being access to, and provision of, reliable data and information (e.g., state of the resources, changes, pressures) and the capacities to interpret correctly and meaningfully this information (Gerlak et al., 2011; Roehring, 2002). Water management and hydrological modeling intrinsically require integration of data, information and models due to their interdisciplinary complex nature (Argent, 2004; Buytaert et al., 2012; Papajorgji, 2005).

Currently, it is recognized that the lack of systematic monitoring and access to reliable time-series on environmental and socio-economical data, suitable for statistical analyses, are a major barrier to effective and efficient informed policymaking (UNEP, 2012). This problem has been recently addressed by several EU funded projects related to water (e.g. ACQWA, enviroGRIDS, GEOWOW) (Fig.1). They all highlight the main obstacle to attaining the objectives of these projects (to 
guide and inform policy) that is the lack of access and availability of data (Beniston et al., 2012). This is also illustrated by research developments in the field of chemical monitoring and discussions about standardization needs in support of the wide-scale river basin monitoring programmes required by the Water Framework Directive (Quevauviller et al., 2007). In summary, many policy-relevant research areas are still facing the problem of readily and timely access to, and exchange of, data.

\subsection{Spatial Data Infrastructure (SDI)}

Supported by the latest technological advances in Earth observation and Web technologies, Spatial Data Infrastructures (SDIs) have been developed and implemented at an accelerated pace recently, both at regional and national levels, with the long term vision of creating a global SDI. The benefits of SDIs have been analyzed and reported extensively (Campagna and Craglia, 2012; Heumesser et al., 2012), as they allow for trans-sectorial and trans-national sharing of, and access to, geospatial data. In addition, their assimilation (consumption) in novel and inventive software applications has provided a wide range of social, economic and environmental benefits. For achieving these purposes, SDIs provide a suite of services for data publishing, discovery, gathering and integration, which enable interoperability of the different components involved. Therefore, the concept of SDI has been developed to facilitate and coordinate the exchange and sharing of geospatial data, encompassing data sources, systems, network linkages, standards and institutional issues involved in delivering geospatial and information from many different sources to the widest possible group of potential users. The objective of an SDI is to provide a framework for incorporating different databases, ranging from the local to the national/regional, into an integrated information highway in order to make 
effective use of the geospatial data needed by a particular community.

Interoperability is the essential condition for developing an open science framework, allowing scientists and researchers to publish, discover, evaluate and access data (Vaccari 2012). Current technologies are suitable to match these requirements only if open software interfaces and standards are established, allowing these technologies to interoperate at a global scale (McKee 2010). The Open Geospatial Consortium (OGC), the leading international voluntary consensus geospatial standards development organization, aims to develop and provide such standards enabling communication and exchange of information between different systems with differing operational software.

The OGC is providing a suite of standard specifications to search and discover geospatial resources (Fig. 1). These resources can be maps provided via Web Map Services (WMS), vectors and raster data published respectively as Web Feature Services (WFS) and Web Coverage Services (WCS), or processing algorithms exposed as Web Processing Services (WPS). Data and services can be documented through International Organization for Standardization (ISO) 19115 (resource metadata), 19139 (metadata encoding) and 19119 (service metadata). These standards are complemented by the OGC Catalog Service for the Web (CSW) specification defining an interoperable interface to publish, discover, search and query metadata.

Metadata are an essential component of the information chain as they enable users to understand the provenance, content, and quality of data. This in turn allows the user to interpret them and integrate them meaningfully with data coming from other sources (Nogueras-Iso, Zarazaga-Soria et al. 2005). Recently, the OGC has also released a suite of standards known as Sensor Web Enablement (SWE) that provide interfaces to manage and access (e.g., discovery, processes, observations, tasking, alerts) real time 
data from sensors that are continuously monitoring and measuring various environmental variables such as water descriptors (Horsburgh et al., 2010; Quinn, 2011).

The water (hydrology) domain has two kinds of relations with the concept of SDI. Firstly, hydrological data and data collected and produced from this application domain may be provided as integral part of a given SDI (to be used by other application domains). Secondly, the water domain significantly benefits from using other relevant geospatial data from the SDI for its own purposes and objectives. A SDI is therefore normally developed with a much broader scope than just a single domain (such as water). Although there are initiatives for developing services for data publishing, sharing and integration in the water domain (e.g. Global Runoff Data Centre, International Groundwater Resources Assessment Center), these constructs by themselves are rarely characterized as SDIs. Since SDI concepts did not fully reach the hydrology community, there is a need for harmonization and alignment of both approaches, as a source of data and as a beneficiary from other sources of data. The water domain has some specific characteristics when considering its relationships with SDI. Much of the data needed in hydrology are geospatial data that existing SDIs already provide (e.g., DEM, land use, soil characteristics, precipitation stations). However, in most cases such data are being combined with other domain-specific application data, in order to setup different kinds of models used for assessment, prediction or forecasting purposes. The kind of models used depends on the specifics of the application domain (e.g., floods, droughts, municipal water supply and drainage, agricultural irrigation and drainage, environmental applications, aquatic biodiversity loss, catchment development, navigation). Such modeling results, properly validated, may then be provided back to a SDI for usage by other application 
domains. In this regard, merging and seamless integration of raw geospatial data and domain-specific data for modeling purposes is one of the key future challenges.

\subsection{Main international and European SDI initiatives}

Several initiatives are promoting the implementation and development of SDIs targeting the water domain (Fig. 1). At the global level, the Global Earth Observation System of Systems (GEOSS) (GEO secretariat 2005) has a dedicated Societal Benefit Area dedicated to Water ${ }^{1}$ and related activities like the Water Cycle Integrator or the Interoperability Experiments on Weather, Ocean, and Water. Similarly, the Eye on Earth initiative has recently launched a special programme on Water Security ${ }^{2}$. At the European level the directive on "Infrastructure for Spatial Information in the European Community" (INSPIRE) (European Commission 2007) has a "CrossBorder Water Management” Initiative ${ }^{3}$ to contribute to the implementation of the Water Framework Directive.

The European Water Framework Directive (WFD) that was adopted in 2000 largely determines the policy developments within Europe regarding the water domain. The WFD provides the legislative basis for catchment-based water management plans (also for international river basins), which are implemented within a specified time period to achieve the objective of "good" ecological and chemical status (as defined by series of indicators) for surface waters and "good” quantitative and chemical status for ground waters of all European water bodies. Consequently, European policy encourages the integration of the water domain ${ }^{4}$ with SDI developments essentially

\footnotetext{
${ }^{1}$ http://www.earthobservations.org/geoss_wa.shtml

2 http://www.ogcnetwork.net/system/files/EoE\%20SI\%20Water\%20Security\%20-12for\%20Summit.pdf

3 http://inspire.jrc.ec.europa.eu/index.cfm/pageid/42/list/7/id/2688

4 http://ec.europa.eu/environment/water
} 
through the WFD and INSPIRE directives, but also with the Drinking water (1998), Bathing water (2006) and Flood Risk Management (2007) directives. For reporting the progress made in the implementation of river basin plans, the WFD requires the usage of geospatial information that should be made available according to the INSPIRE principles and technical specifications. These activities critically depend on geospatial (and non-geospatial) data, as well as on application of various hydrological, hydraulic, water quality and other environmental models, which in their turn can significantly benefit from standardized and open data sharing and exchange. SDIs will be also essential for new initiatives such as Eyes on Earth ${ }^{5}$ that is building building interactive and attractive web interfaces to explore, contribute and create new ways of looking at the environment. Future Earth $^{6}$ is as a new 10 -year long project built on the existing global environmental change programmes (Diversitas, IGBP, IHDP, WCRP, ESSP). This project aims at federating the scientific community while strengthening partnerships with policy-makers after the United Nations Conference on Sustainable Development conference (Rio+20). These different international initiatives build on the concept of Digital Earth proposed by Al Gore in $1998^{7}$, where citizen could access a virtual globe describing the environmental and cultural state of the planet. Private sector developments such as Google Earth have gone a long way to put the vision of Digital Earth into practice, although to date the quantity and quality of scientific data exposed by these systems is very limited. The opportunities created by these new developments together with the rise of social networks, mobile computing, and cheap sensors, have spurred a revised vision of Digital Earth to guide its implementation in the years to come (Craglia et al., 2008,

\footnotetext{
5 http://www.eyeonearth.org

6 http://www.icsu.org/future-earth

7 http://www.isde5.org/al_gore_speech.htm
} 
Goodchild et al. 2012).

\subsection{Selected European projects in hydrology}

A series of recent European projects are promoting SDIs in the research community while favoring the uptake of their scientific outcomes for water policy enhancement

(Fig.1). The ACQWA ${ }^{8}$ project aims at assessing the impact of climate changes on water resources in mountainous regions with case studies in different catchments (Rhône, Po, Pyrenees, Chili and Kirgizstan). The main outputs of this project will be made available through its dedicated SDI platform. EnviroGRIDS ${ }^{9}$ is targeting the Black Sea full catchment (Lehmann et al. 2014) by modeling its hydrology for the first time as a whole (Rouholahnejad et al., 2013a), while predicting future water resource vulnerabilities as a function of scenarios involving climatic, demographic and land cover changes (Rouholahnejad et al., 2013b). Here again, the datasets produced by the project will be made available through a Grid-enabled SDI registered into GEOSS. A Black Sea Observation System was developed with several components linked to Grid computing infrastructures (Gorgan et al. 2013) and with a decision support tool called BASHYT (Cau et al. 2013). GEOWOW ${ }^{10}$ is developing functionalities to improve access to weather, ocean and water data and resources through users-friendly ways to query, discover and access data that are made available through the GEOSS Common Infrastructure $\left(\mathrm{GCI}^{11}\right)$. Finally, the STEP-WISE ${ }^{12}$ project aims at bridging the science water policy gap in order to improve the WISERTD web platform and link directly the outputs of research projects with the adequate

\footnotetext{
8 http://www.acqwa.ch/

${ }^{9}$ http://www.envirogrids.net

10 http://www.geowow.eu

11 http://www.earthobservations.org/gci_gci.shtml

12 http://www.spi-water.eu
} 
water policy instruments.

(FIGURE 1)

\subsection{Success stories involving hydrologists' communities}

The Water Information System for Europe (WISE) ${ }^{13}$ is a web-based service started in 2007 that aims to act as a gateway for water related information (e.g., from inland waters to marine ecosystems) covering several topics (EU water policies, data and themes, modeling, projects and research) for the benefit of different user groups (EU institution and Member States, Professionals, Scientists, General public). WISE is now regrouping plenty of users across Europe reporting on water quality measures at the basin scale to inform the Water Framework Directive.

Since 2012 EFAS $^{14}$ is an operational service under the umbrella of the Copernicus emergency management service that is run by Member States organizations. EFAS is an early flood warning system complimentary to national and regional systems that forecasts river flooding within the next 3 or more days. The forecasts are made available first to the Member States authorities as flood warnings are within their responsibilities. Only archives can be made publically available.

Another good example of integration of water issues in SDIs is the distributed information system developed by the Consortium of Universities for the Advancement of Hydrologic Science (CUAHSI ${ }^{15}$ ). This web-based system allows storing, publishing, sharing, processing, and analyzing hydrological data through a full suite of software and standardized/interoperable services (Ames et al., 2009). Another example comes from the Committee on Earth Observation Satellites

\footnotetext{
13 http://water.europa.eu

14 http://floods.jrc.ec.europa.eu/efas-flood-forecasts.html

15 http://www.cuahsi.org
} 
$\left(\mathrm{CEOS}^{16}\right.$ ) Water Portal led by Japan Aerospace Exploration Agency provides assistance to the water relevant scientists and general users in the development of data services associated with data integration and distribution. Additionally, the OGC has several projects underway related to water resources ${ }^{17}$. In particular, the OGC Hydrology Domain Working Group seeks to develop and provide solutions to the challenge of describing and exchanging data related to water resources.

The World Meteorological Organization (WMO) developed its Information system $\left(\mathrm{WIS}^{18}\right)$ that is the global infrastructure responsible for the telecommunications and management of data. It represents the WMO strategy for moving weather, climate and water information in the 21st century. WIS provides an integrated approach suitable for all WMO Programmes to meet the requirements for routine collection and automated dissemination of observed data and products, as well as data discovery, access and retrieval services for weather, climate and water data.

Finally, the Integrated Global Water Cycle Observation (IGWCO) is contributing to the Global Earth Observation System of Systems (GEOSS) in the form of strategic guidance, coordination, and gap analysis with the aim of developing an integrated, sustained operational global water cycle observation system. In addition, the IGWCO has been active in the establishment of a Water Cycle Community of Practice (WCCoP), to connect decision makers with Earth observations experts.

In this very dynamic context, the aim of this paper is to review the current gaps in term of data discovery, accessibility, processing/modeling in hydrology and to highlight existing and potential solutions brought by Earth observations to support hydrological modeling activities and policy making.

\footnotetext{
16 waterportal.ceos.org

17 http://www.opengeospatial.org/node/1535

18 www.wmo.int/wis
} 


\section{Gaps between water research and policy making}

\subsection{Managing multiple data sources}

The most important data for hydrological modeling is certainly weather data as it is a driving variable. These data usually come from weather stations that make measurements of temperature, rainfall, solar radiation, wind speed, and relative humidity at regular time intervals from a few hours to a few days (Rahman et al. submitted). The spatial distribution of the stations is very heterogeneous, both intranational and varying across the world between data rich and data poor countries. The quality of the data is often questionable because of data gaps and observational bias, Furthermore, these essential data remain difficult to obtain because it is still very protected in most countries. An alternative to weather station data can come from the results of reanalysis (e.g. $C R U^{19}$, ECA\&D ${ }^{20}$ ).

Water quantity and quality are other important hydrological data that are needed especially for the calibration of hydrological models. Most countries measure the water quality and quantity of their rivers but this information is often heterogenous and difficult to obtain. Initiatives undertaken by global data centers such as the Global Runoff Data Center (GRDC ${ }^{21}$ ) and the Global Water Monitoring System (GEMS ${ }^{22}$ ) should receive much more attention in order to be able to truly become the reference for global data repositories. Furthermore, information such as crop yield and agricultural management (e.g., irrigation and fertilization) were also shown to be essential for a more accurate calibration of water quality and water balance components in hydrological models (Faramarzi et al., 2009).

\footnotetext{
19 http://www.cru.uea.ac.uk/data

20 http://eca.knmi.nl

21 http://www.bafg.de/GRDC

22 http://www.gemstat.org
} 
GIS data such as digital elevation models (DEM), land cover and soil characteristics are becoming increasingly available with higher resolution and quality even at the global scale. They can be complemented by remote sensing imagery with sensors such as the Moderate Resolution Imaging Spectroradiometer (MODIS) that is covering the entire globe at medium resolution almost everyday.

Global and regional outputs from climate models are also very important to explore the future of water resources through hydrological models. Such data are available through various leading organizations (e.g. $\operatorname{IPCC}^{23}$ ) but can be difficult to manipulate due to their large intrinsic uncertainty, their multiple dimensions and their low resolution (typically between $25 \mathrm{~km}$ and $100 \mathrm{~km}$ ). Statistical downscaling can bring this data to $1 \mathrm{~km}$ resolution, but this remains still far from the few meters' resolutions increasingly needed in climate change impact studies.

\subsection{Dealing with data heterogeneity}

Organizations at various geopolitical levels (e.g., regional, national, sub-national) are measuring different important variables for hydrology such as streamflow, water quality, soil moisture and precipitation. Thus, these data repositories contain represent sources of potentially useful data. However, data collection and publication methodologies are in general different (e.g., data storage, formats, mean of retrieval).

Consequently, integrating hydrological data from various heterogeneous data sources to develop models or make hydrological analyses remains a major problem (Horsburgh et al., 2009). Typical data formats include tabular datasets (e.g. Excel, CSV, DBF), documents/images (e.g. PDF, JPEG, Word), (geospatial) databases (e.g., PostgreSQL/PostGIS, Oracle, Access), geospatial data formats (e.g. shapefiles, grids,

\footnotetext{
${ }^{23} \mathrm{http}: / /$ www.ipcc-data.org
} 
geotiff). Additionally, some past hydrological measurements have not yet been digitized.

\subsection{Struggling with data sharing}

Beniston et al. (2012) have reported that researchers in climate and water sciences are regularly facing the problem of searching, finding, and accessing data. These authors have highlighted several barriers that are impeding a timely and efficient usage of water-related data. In particular, incomplete and non-standardized time series data are a major stumbling block, causing scientists to spend extra time in data gathering and harmonization (Hannah et al., 2011). Moreover, these data are often redundant because of the lack of coordination between the various data producers. This situation leads to the fragmentation of repositories (Reed et al. 2010), making them difficult to discover even if they are available. Data are often poorly documented (i.e., missing or incomplete metadata) which means users cannot evaluate the suitability of the data for particular purposes. Search and download interfaces are often complex and difficult to understand for non-experts. Therefore, facilitating the exchange and access to waterrelated data is essential (Beniston et al., 2012) to easily integrate them with other distributed data sources (Lee et al., 2007). This requires implementing/endorsing some commonly agreed standards. In particular, documenting data with adequate metadata and making them searchable through catalogs is a pre-requisite to facilitate data search and discovery. In this respect, the implementation of the INSPIRE Directive will do much to address this situation in Europe, while the development of the GEOSS Data -CORE, a pool of resources with full and open access addressing key environmental domains including water, needs to be fully supported to overcome existing policy differences at the global level. Notwithstanding these important 
developments, further difficulties affecting data sharing include policies on data commercialization, protection of intellectual property through restrictive copyrights, the existence of linguistic and geopolitical barriers, and the reluctance by older generations to adopt new technologies. These difficulties are particularly stringent in emerging economies where government leadership is frequently missing (Strobl et al., 2012). The potential barriers (legal, economic, conflict of interest, misuse, data quality or practical barriers) to the exchange of hydrometeorological data were reviewed by Viglione et al. (2010) with a survey in 32 European countries. They conclude that the most important perceived barriers by both data users and producers are legal and economical.

Earlier, Saarikivi et al. (2000) analyzed the difference in data sharing practices between Europe and the USA demonstrating how the choice of European administrations to try to sell hydrological and meteorological observations was very dangerous for the development of hydrology in this continent. On the contrary, the USA favor an opposite direction for several reasons: worldwide science would suffer; conflict between nations would increase; U.S. policy and laws would be undermined; and healthy competition would be harmed.

\subsection{Improving data processing}

Supported by technological innovations (e.g., Web Services, Web 2.0) and greater affordability of digital devices, we are currently seeing a deluge of data in term of quantity and diversity (e.g., real-time, archived, crowd-sourced, high-resolution) (UN Global Pulse, 2012). This poses new challenges and offers new opportunities to turn these data into understandable, usable information. Consequently, efficient processing solutions are required, and distributed high performance computing infrastructures 
such as Grids or Clouds appear as promising solutions (Bosin et al., 2011; Fraser et al., 2007; Giuliani et al., 2011). Indeed, there is an increasing need for large computational power to answer the demand for large scale, yet fine resolution modeling. Moreover, uncertainty and sensitivity analysis require integration of different sources of geospatial data, provided by SDIs via diverse web services, together with other domain specific data within Grid or Cloud computing environments. Thus, efforts are underway to better understand and model hydrological systems (Ray et al., 2012), supported by SDI and Distributed Computing platforms (Diaz et al., 2008; Goodall et al., 2011; Lecca et al., 2011; Paudyal and McDougall, 2008; Tarboton et al., 2009). The enviroGRIDS research project aimed to achieve such integration through the development of a Grid-enabled SDI for the entire Black Sea catchment (Giuliani et al. 2013a) that can feed data into the Soil and Water Assessment Tool (SWAT, Arnold et al., 1998). The goal of this integration is to enable analysis of future climate impacts, development-induced land use and demographic changes on several key social benefit areas in the catchment, such as agriculture, energy, health, flood disasters, ecosystems and biodiversity.

\subsection{Challenging river data visualization}

One of the obvious challenges in representing hydrological data is the linear shape and length of river segments, plus the multidimensional content of their description, that are both difficult to represent on maps. The Internet is a powerful medium to support search, visualization and access to geospatial and observational time-series in a single environment and can leverage the potential of water resources information (Hannah et al., 2011; Huang et al., 2011). Indeed, useful statistics and indicators 
regarding water quantity and quality are provided on various websites ${ }^{24}$. An emerging requirement for river data visualization is to allow exploring data with interactive tools. Currently, large amount of hydrological data can be visualized as static maps (in PDFs or images) or tables (PDF or HTML) representing one specific variable. However, this impedes users to easily compare data, identify areas under pressure, or sort data. Moreover, spatial and temporal variation patterns in the data - an important property of variables linked to natural resources - may not be readily identifiable through static representations. A Geographical Information System (GIS) supports both geospatial and time-series data. It enables users to handle data and to visualize it as interactive maps or graphs (Ames et al., 2009; Kao et al., 2011). An example of data visualization and its importance in hydrological model calibration is the SWATCUP software (Abbaspour, 2011) that combines shape files of any kind of information with the Bing map to create a real time visualization of model inputs (e.g., rainfall, temperature, outlets, etc.) and model outputs (e.g. water resources in terms of blue and green water, water quality).

\subsection{Coping with data quality and uncertainties}

Improving the access to existing data is necessary, but it is not sufficient. Scientists know that the quality of the data that they use is essential to guarantee the quality of their outputs. Unfortunately hydrology being dependent on many data sources is particularly exposed to the risks inherited errors (lack of precision, accuracy) and uncertainties due to the method used to create the data. By combining several sources of data, hydrological models typically suffer from the uncertainty of their input data

\footnotetext{
24 http://www.unwater.org/statistics_KWIP.html $\underline{\text { http://open-data.europa.eu/en/data/dataset/qhmuzTnG97kJPDEUJrsnQ }}$ http://www.worldbank.org/en/topic/water
} 
being combined in complex ways into their outputs (Abbaspour et al. 1996). The use of different possible hydrological models is even a source of uncertainty itself (Moran et al. in prep). Finally, hydrological information, as a natural science, has not been linked to other sources of information coming from economical and social sciences. However, it appears that in order to fill the gap between science and policy, both quantitative and qualitative information needs to be integrated in hydrology (Quevauviller 2002; King 2011).

\subsection{Brokering approach}

Understanding the complexity (e.g., interactions, multi-dimensionality, continuously evolving, spatial and temporal scales, cross-disciplinarity and multi-organizational challenges) of water system requires gathering and integrating different data sets about physical, chemical and biological system, often provided by different organizations. Consequently, a collaborative and multi-disciplinary effort to provide an integrated access to a wide range of services and resources on water is needed. This obviously raises the challenge of a multi-stakeholder participation. A top-down approach would emphasize the need for standardization and uniformity, while a bottom-up approach would stress the importance of diversity and heterogeneity due to the different mandates and aspirations of the various stakeholders (see for example Strobl et al. 2012). Consequently, it is necessary to find a consensus to ensure some measure of standardization and uniformity while recognizing the diversity and the heterogeneity of the different stakeholders performing different tasks at different

levels. Therefore, a suitable approach to tackling this issue is the so-called System of Systems (SoS) exemplified by GEOSS. This initiative underpins a multi-disciplinary framework building on existing systems. They recognize the heterogeneity of systems 
reflecting the diversity of stakeholders and does not seek to impose a single suite of standards on all the different communities involved. Such a framework provides notable features, such as: (1) each component can operate independently (e.g., in order to match its own objective) and can be connected to others component by agreeing and specifying interoperability arrangements; components can grow and be cured autonomously, providing more flexibility, (2) increasing the capacity to turn data into information by sharing resources, (3) providing a holistic approach, (4) supplementing but not supplanting existing systems, (5) enhancing composability of resources, (6) avoiding single point of failure, (7) being service oriented, and (8) incorporating incrementally new components/systems. This approach is also interesting as it lowers the present entry-level barrier, which translates into implementing only a few standards to achieve at least syntactic interoperability. However, the SoS approach needs to address important interoperability challenges, including: semantic composability, different interoperability/maturity levels of the systems, architecture scalability and extensibility, sustainability, flexibility, and diversity of standards. Noticeably, the latter is pertinent due to the fact that in the Earth and space science community there are hundreds of different standards and best practices, making it impossible for client developers to implement all of them. Considering this and several of the introduced challenges, standardization effort must be complemented with an intermediation approach: introducing gateways (i.e. brokers). Brokers intermediate client and server components by implementing the service interfaces used by servers and exposing clients to only the set of common standards they use. This so-called brokering approach (Craglia et al., 2008; Nativi and Bigagli, 2009; Nativi et al., 2013) allows binding heterogeneous resources published by different data providers (e.g., by reading and mediating different standards and 
specifications used by various scientific communities), and adapting them to tools and interfaces commonly used by users of these resources (Fig.2). This enables interconnections between communities allowing to search, discover, and access heterogeneous resources, while letting users and data providers to continue using their tools and publishing their resources via their usual standards. Consequently, the SoS framework supported by brokering approach can ease commitment and facilitate endorsement and acceptance on interoperability allowing interconnecting different systems and providing a real multi-disciplinary framework for integrative research. The need for brokering is particularly acute in the water policy area, which mixes a wide variety of disciplines and actors from science, policy-making and the civil society, and which requires a well-structured science-policy interface to ensure a constant flow and transfer of information (Quevauviller, 2010).

\section{(FIGURE 2)}

\section{Bringing hydrological modeling closer to policy making}

\subsection{Dynamic model infrastructure}

GEOSS is supporting the concept of Model $\mathrm{Web}^{25}$, a dynamic modeling infrastructure where various resources (e.g., data, models, algorithms) are published as web services and can be integrated/chained to develop complex and multi-component models (Nativi et al. 2012). This concept envisions a loosely coupled system allowing modelers to develop, manage, and operate their models independently while exposing them to commonly agreed interfaces. Compared to tightly coupled/closed systems,

\footnotetext{
25 http://www.earthobservations.org/documents/tasksheets/latest/AR-09-02d.pdf
} 
this approach brings many benefits while avoiding strong central control, offering more flexibility and scalability, increasing accessibility to resources, and enhancing reproducibility and transparency of models (e.g., repeatability, comparison of outputs). Implementing such a Model Web framework asks for data and models interoperability (Bastin et al. 2013). This ability to exchange information unambiguously and use it by different systems or components requires syntactic (e.g., capacity to communicate/exchange information), semantic (e.g., interpret meaningfully and accurately the information that has been exchanged), and schematic (e.g., data models) interoperability (Open Geospatial Consortium, 2004). Consequently, such interoperable web-based distributed modeling frameworks offer the potential to develop holistic environmental models through complex workflows (Bastin et al. 2013; Horsburgh et al., 2011).

\subsection{Emerging hydrological data standards}

Currently, the OGC has several projects underway related to water resources ${ }^{26}$. In particular, it has a Hydrology Domain Working Group that is seeking to develop and provide solutions to the challenge of describing and exchanging data related to water resources. For example WaterML 2.0 has been accepted as an OGC standard ${ }^{27}$. This is an XML-based specification used to formally describe hydrological data and act as an interchange format via the Internet through web services. It contains specifications for point and spatial coverage data (via XML elements) as well as a set of generic vocabularies. Additionally, the OGC is conducting Interoperability Experiments on Surface Water, Ground Water, and Hydrologic Forecasting, as well as developing pilot studies on Hydro-climatology Information Sharing. WaterML does not start

\footnotetext{
26 http://www.opengeospatial.org/node/1535

$27 \mathrm{http}: / /$ www.opengeospatial.org/projects/groups/waterml2.0swg
} 
from a high level ontology (formal specification of a conceptualization of a domain, with objects and their relations), that somehow attempts to describe all the processes in the hydrological cycle, but concentrates on hydrological data themselves and their spatial characteristics. WaterML has certainly the potential for becoming a standard markup language for exchanging generic hydrological data. However, as mentioned earlier, the water domain in fact comprises a number of application domains, each potentially requiring its own, different ontology and different XML-specification / description. In other words, it should not be expected that this kind of standards development would be a panacea for solving all interoperability challenges. Domainspecific ontology development will still be required. Here the advantages of the XML format in being both human and machine readable are becoming apparent, as this enables designers of client software applications that utilize given web service to find out what is the underlying ontology (formal specification).

\subsection{New data sources}

New remote sensing missions and sensors are producing valuable information to improve our understanding and modeling of the water cycle, estimating valuable information on soil moisture and water salinity (SMOS: Kerr et al. 2010), groundwater (GOCE: Rummel et al. 2011), and ice and snow (CryoSat). These are made available by ESA with a open data policy ${ }^{28}$. Field sensors are also developing rapidly and becoming cheaper. This will certainly improve spatial and temporal coverage of essential information on weather and hydrology in the future. Finally, the use of crowd sourcing (Goodchild et al. 2012) has the potential to make use of a large number of contributors of valuable information on the water system (Fienen and

\footnotetext{
28 https://earth.esa.int/web/guest/-/revised-esa-earth-observation-data-policy-7098
} 
Lowry 2012), for instance on water quality, biodiversity or pollution. Uniform and systematic quality assurance, however, remains a challenge with respect to data provided through crowd-sourcing means.

\subsection{Models integration}

The vision of a processed-based infrastructure providing reusable and standardized components matching users’ needs is supported by the Service Oriented Architecture (SOA) concept. Services are the basic component representing a set of operations allowing users to invoke and access resources (e.g. data, calculations, models). The OGC specifies a suite of standards that allow providers to publish interoperable services to access distributed resources over the Internet using Uniform Resource Locators (URLs). Using such interoperable web service can leverage the interoperability, allowing to users to seamlessly couple and reuse those services in different applications/contexts. This mechanism of combining web services to create customized application is known as service chaining (Granell et al. 2009). By chaining and organizing coherent series of web services, users can process data whereby new knowledge emerges from relationships that were not envisioned before (Open Geospatial Consortium 2004) and users can achieve larger tasks (Di 2004). Therefore service chaining offers the possibility to (1) build complex analysis tasks, (2) use heterogeneous resources, and (3) data exchange between models. However, coupling models (especially tools that require time step basis as they run) will also require standard interface like OpenMI to enable modeling process interactions (e.g., different suppliers, processes from different domains, different concepts, different spatial and temporal resolutions, different representations) (Goodall et al., 2011). Moreover, running models as a chain of web processing services is suitable for 
relatively simple models. Very complex ones (e.g. in the meteorological domain) cannot be realistically run in such a way.

\subsection{Processing complex hydrological model}

In the enviroGRIDS project, the need for improved processing capacities became obvious during calibration of the Soil and Water Assessment Tool hydrological model when high-resolution data were used at the scale of the full Black Sea catchment (amounting to more than 12'000 sub-basins). On the one hand, new SWAT parallelization solutions were tested (Rouholahnejad et al. 2012, Yalew et al., 2013) and on the other hand, a web-based application was developed to run SWAT on the

GRID (gSWAT: Gorgan et al., 2012, Bacu et al. accepted). Knowing that SDIs have limited analytical capacities, Giuliani et al. (2011) proposed an approach to seamlessly execute a geoprocessing calculation on different computing back-ends, ranging from a stand-alone GIS server to Grid infrastructures by mediating geospatial and Grid packages through an extension of the WPS specification with two optional parameters.

\subsection{Incorporating the temporal dimension}

Water systems are complex and dynamic; therefore space and time-varying aspects are central to accurate representation and understanding of phenomena. OGC WFS and WCS specifications are intrinsically suited to represent such variations and can enable the development of models that can take into account this fundamental requirement. Such benefits have been exemplified in the BRIdging Services Information and Data for Europe (BRISEIDE) project in which data models were extended with a time-aware component and coupled with a web-based, integrated n- 
dimension visualization client enabling interactive spatio-temporal visualization, management, publishing, authoring, and processing of geospatial data (De Amicis et al., 2010; Prandi et al., 2012). Additionally, clients such as Google Earth or NASA World Wind are now able to offer capabilities to visualize 2D, 3D, and temporalaware data in a simple and efficient way using OGC standards like WMS and Keyhole Markup Language (KML) (Sun et al., 2012).

NetCDF is a particularly interesting data format especially used in climatology and oceanography. Being multidimensional, NetCDF easily incorporates the three spatial dimensions and time, allowing dynamic 4D visualization. It has also the advantage of integrating the metadata description inside the dataset itself, avoiding separation of the two. Furthermore, it became recently possible to expose NetCDF datasets through web services thanks to the THREDDS solution (Signell et al. 2008). These characteristics should convince the Earth observation community to widen the use of NetCDF as a standard for data sharing and storing.

\subsection{Dealing with uncertainty}

Ensemble forecasting (Leutbecher and Palmer, 2008) was developed by climatologists to deal with uncertainty found in dynamic models by varying initial conditions, model parameterizations or models components. This approach is now spreading in other disciplines such as ecology or hydrology, raising the question as to whether it is better to use an averaged forecast, versus selecting a particular trusted model, data and/or parameterization to guide further decision making. Model inputs can be either data or outputs of other models but in any case the inputs will be subject to errors, contributing to the uncertainty of model outputs. This error propagation must be quantified together with the modeling processing itself. However, current 
web-based modeling frameworks are facing the problem of managing uncertainty with respect to data and models (Bastin et al. 2013). Policy and decisions-makers are increasingly relying on scientific data and model outputs to explore different scenarios and take or develop better-informed decisions/policies (Buytaert et al., 2012). Therefore, having the means to quantify and efficiently communicate uncertainty of data and models appears an essential pre-requisite. Otherwise, providing incomplete information can negatively influence decision-making processes and development of adaptation strategies to inrepsonse to the pressing challenges we are currently facing (e.g., climate change, energy supply, water scarcity). To tackle this issue, it is required to enable uncertainty propagation in models and propose an interoperable representation of uncertainty. The UncertWeb ${ }^{29}$ modeling framework (Bastin et al. 2013) is an attempt to act as an uncertainty management system supporting the "Model Web" by providing tools supporting elicitation, aggregation/disaggregation, visualization, and uncertainty/sensitivity analysis in complex service chains. UncertWeb is based on the Uncertainty Markup Language (UncertML ${ }^{30}$ ), proposing a conceptual model and XML encoding to communicate probabilistic uncertainty (Pebesma et al., 2011).

\subsection{Data policies}

SDIs and related concepts, methods and technologies appear promising to support and facilitate water-related data discovery, accessibility, visualization, dissemination, and analysis. On a technical level, all the building blocks are available supported by the interoperability standards and frameworks. SDIs have the potential to be part of the answer to bridging the gap between scientists and decision/policy makers by

\footnotetext{
29 http://www.uncertweb.org

${ }^{30}$ http://www.uncertml.org
} 
providing tools to access reliable water-related information rapidly, efficiently, and meaningfully. Henricksen (2007) stated that to achieve the objective of successful SDI implementation, the key requirement is that institutions and people must be willing to work together and share a common vision. Among the most frequent obstacles to achieving this vision, however, is the lack of institutional and political wills to publish and share data is frequent (Nebert, 2005). Indeed, data providers tend to limit access to data mostly for confidentiality, national security or "misuse prevention” reasons. This inevitably leads to duplication of activities, duplication and fragmentation of data, overlaps between initiatives and projects, lack of coordination, insufficient flow of information, and inadequate resources management. Additionally, insufficient staff skills can cause a lack of standardization (e.g., data, metadata, procedures) and lack of documentation on who is doing what, and what is available. This incoherent, inconsistent and unshared vision of a SDI induces: (1) difficulties in finding/accessing required data, and (2) lack of knowledge from data providers about the value of what they have. Altogether, these reasons preclude a reliable organization for data dissemination purposes and prevent enhancement of the value of integrated information. Cooperation is strongly influenced by political and organizational factors such as institutionalized historical practices or dominating legacy systems and standards. Moreover, resistance can appear if the perceived complexity of (top-down) SDI initiatives do not directly relate to the own/local objectives and mandates of an institution, organization or a country. Therefore it is important to consider appropriately requirements of each stakeholder that need first to fulfill their own mandate. Consequently, organizations are intending to cooperate only if they can perceive benefits. To make cooperation successful in SDIs, various elements are essential: a shared vision between all participants, necessity to solve a dominant 
problem, incentives, and sufficient resources (Salzmann, 2011). Actions can be initiated by legal regulations (like in USA or in Europe) adopting Open Data policies that promote and ensure easy access to data so that they can be used as often and widely as possible. For example in Europe Open Data initiatives ${ }^{31}$ are starting to make an impact in respect to both public sector information, and scientific data, while the Research Data Alliance ${ }^{32}$ has been established to accelerate and facilitate research data sharing and exchange at the global level.

\subsection{Capacity building}

Capacity building at human (education and training of individuals), infrastructure (installing/configuring/managing of the needed technology) and institutional (enhancing the understanding within organizations and governments of the value of geospatial data to support decision-making) levels is a major element for large adoption, acceptance and commitment to SDI concepts inside and outside the GI community (e.g., climatologists, hydrologists, ecologists) (Giuliani et al. 2013b). In particular, showing and proving the benefits of sharing interoperable data/metadata through appropriate examples, best practices and guidelines will help to strengthen (1) existing observation systems, (2) capacities to decision-makers to use it, and (3) capacities of the general public to understand important environmental, social and economical issues. Altogether this will help to reach agreement and endorsement on the use of new standards. Such a participative approach will certainly stimulate data providers to be more "open” and consequently to share their data. The best way to reach this objective is probably through establishment of a long-term commitment to education and research; otherwise the SDI vision will remain unclear and

31 https://ec.europa.eu/digital-agenda/node/70

32 https://rd-alliance.org/about.html 
unachievable. All these actions will help to reach endorsement on the use of such technologies, raising and increasing awareness on the benefits of using and sharing geospatial data, and finally creating new commitments. Figure 3 represents one of many possible integrations of emerging SDI solutions for connecting data to endusers needs.

(FIGURE 3)

\section{Conclusions and perspectives}

Currently, hydrological, meteorological and agricultural data remain difficult to find, access, and integrate because of various incompatibilities (data formats, models, quality), missing documentation (metadata), data fragmentation and replication, nonexisting or inappropriate data policies, and isolation of operating systems.

International initiatives following the System of Systems approach, such as GEOSS and legal frameworks such as INSPIRE in Europe, catalyze data sharing by promoting interoperability to maximize the (re)use of data and supporting easy access to and utilization of geospatial data. The System of Systems framework supported by a brokering approach interconnects different systems and provides a real multidisciplinary framework. SDI concepts, methods and technologies certainly represent an important step toward removing barriers to data availability, accessibility, integration, and modeling. These concepts provide guidance for storage, diffusion and exchange of data, permitting faster and easier update while fostering new collaboration and cooperation between various scientific disciplines, potentially allowing better understanding and interconnections of water-related processes, enabling scientists to compare results, models and methodologies more easily, 
bringing more reliable information and knowledge, increasing scientific accountability and credibility, and ultimately leading to better-informed decisions by water managers.

Innovative solutions are emerging such as new OGC standards (such as WaterML, netCDF) that are enhancing interoperability between hydrology and other scientific disciplines. This is also facilitating the sharing of models and specific algorithms using the Web Processing Services (WPS), allowing data to be processed on demand and models to be interconnected and processes through complex workflows. Distributed computing infrastructures can handle complex and large hydrological data and models. These infrastructures allow processing data more rapidly, running models at higher resolution (both spatially and temporally), and improving the robustness of uncertainty analysis of models. Web processing services bring the flexibility to run simple to complex workflows on the fly over the Internet.

With all these technological improvements, large steps are being made to improve the science-policy interface as illustrated by the WFD Common Implementation Strategy (e.g. in Quevauviller, 2010). The most difficult step however remains to bring scientists and decision-makers around the same table to build their project together with an adaptive strategy. One way forward is through building interdisciplinary projects where several forms of knowledge (scientific, economic, social) are processed, compared and integrated to provide a holistic context within which important decisions may be informed and negotiated.

\section{Acknowledgements}

The authors would like to acknowledge the European Commission "Seventh Framework Program” that funded the enviroGRIDS project (Grant Agreement no. 
227640), the ACQWA project (no. 212250) and the GeoWOW project (no. 282915).

\section{References}

Abbaspour, K.C., Schulin, R., Schläppi, E., Flühler, H., 1996. A Bayesian approach for incorporating uncertainty and data worth in environmental projects. Environmental Modeling and Assessment, 1: 151-158.

Ames, D.P., Horsburgh, J., Goodall, J., Whiteaker, T., Tarboton, D., Maidment, D., 2009. Introducing the Open Source CUAHSI Hydrologic Information System Desktop Application (HIS Desktop). 18th World Imacs Congress and Modsim09 International Congress on Modelling and Simulation: 4353-4359.

Argent, R.M., 2004. An overview of model integration for environmental applications, components, frameworks and semantics. Environmental Modelling \&amp; Software, 19(3): 219-234.

Bastin, L., Cornford, D., Jones, R., Heuvelink, G.B.M., Pebesma, E., Stasch, C., Nativi, S., Mazzetti, P., Williams, A., 2013. Managing uncertainty in integrated environmental modelling: The UncertWeb framework. Environmental Modelling \& Software 39: 116-139.

Beniston, M., Stofel, M., Harding, R., Kernan, M., Ludwig, R., Moors, E., Samuels, P., Tockner, K., 2012. Obstacles to data access for research related to climate and water: Implications for science and EU policy-making. Environ. Sci. Policy, 17: 41-48.

Bosin, A., Dessi, N., Pes, B., 2011. Extending the SOA paradigm to e-Science environments. Future Generation Computer Systems-the International Journal of Grid Computing-Theory Methods and Applications, 27: 20-31. 
Buytaert, W., Baez, S., Bustamante, M., Dewulf, A., 2012. Web-Based Environmental Simulation: Bridging the Gap between Scientific Modeling and Decision-Making. Environmental Science \& Technology, 46: 19711976.

Campagna, M., Craglia, M., 2012. The socioeconomic impact of the spatial data infrastructure of Lombardy. Environment and Planning B-Planning \& Design, 39: 1069-1083.

Cau P., Manca S., Soru C., Gorgan D., Bacu V., Lehmann A., Ray N., Giuliani G., 2013. An Interoperable OGC-compliant Information and Support System for Water Resources Management. International Journal of Advanced Computer Science and Applications (accepted).

Craglia, M., Goodchild, M.F., Annoni, A., Camara, G., Gould, M., Kuhn, W., Mark, D., Masser, I., Maguire, D., Liang, S., Parsons, E. 2008. Next-Generation Digital Earth: A position paper from the Vespucci Initiative for the Advancement of Geographic Information Science. International Journal of Spatial Data Infrastructures Research, 3: 146-167.

De Amicis, R., Conti, G., Prandi, F., 2010. BRISEIDE - BRIdging Services Information and Data for Europe. Spatio-Temporal Data Management and Processing in the Context of Civil Protection Scenarios, GSDI-12, Singapore, pp. 1-12.

Diaz, L., Granell, C., Gould, M., 2008. Case study: Geospatial processing services for web-based hydrological application, Geospatial Services and Applications for the Internet, pp. 31-47. 
Fienen, M.N., Lowry, C.S., 2012. Social.Water - A crowdsourcing tool for environmental data acquisition. Computers \& Geosciences 49: 164-169.

Faramarzi, M., K.C. Abbaspour, R. Schulin, and H. Yang. 2009. Modeling blue and green water availability in Iran. Hydrological Processes. 23: 486-501.

Fraser, R., Rankine, T., Woodcock, R., 2007. Service oriented grid architecture for geosciences community, Proceedings of the fifth Australasian symposium on ACSW frontiers - Volume 68. Australian Computer Society, Inc., Ballarat, Australia.

Gerlak, A.K., Lautze, J., Giordano, M., 2011. Water resources data and information exchange in transboundary water treaties. Int. Environ. Agreem.-Polit. Law Econom., 11: 179-199.

Giuliani, G., Gorgan, D., 2013a. Editorial: EnviroGRIDS Special Issue on Building a Regional Observation System in the Black Sea catchment. International Journal of Advanced Computer Science and Applications.

Giuliani, G., Nativi, S., Lehmann, A., Ray, N., 2012. WPS mediation: an approach to process geospatial data on different computing backends. Computers and Geosciences 47:20-33

Giuliani, G., Ray, N., Lehmann, A., 2013b. Building Regional Capacities for GEOSS and INSPIRE: a journey in the Black Sea Catchment. International Journal of Advanced Computer Science and Applications (accepted).

Giuliani, G., Ray, N., Lehmann, A., 2011. Grid-enabled Spatial Data Infrastructure for environmental sciences: Challenges and opportunities. Future Generation Computer Systems, 27: 292-303. 
Goodall, J.L., Robinson, B.F., Castronova, A.M., 2011. Modeling water resource systems using a service-oriented computing paradigm. Environmental Modelling \& Software, 26: 573-582.

Goodchild MF, et al. 2012. Next-generation Digital Earth. Proceedings of the National Academy of Sciences of the United States of America 109: 1108811094

Gorgan D., Bacu V., Mihon D., Rodila D., Abbaspour K.C., Rouholahnejad E. 2012. Grid based calibration of SWAT hydrological models. Natural Hazards and Earth System Sciences, 12:2411-2423.

Gorgan D., Giuliani G., Ray N., Lehmann A., Cau P., Abbaspour K., Charvat K., Jonoski A. 2013. Black Sea Catchment Observation System as a Portal for GEOSS Community. Accepted by International Journal of Advanced Computer Science and Applications.

Hannah, D.M. et al., 2011. Large-scale river flow archives: importance, current status and future needs. Hydrol Process, 25: 1191-1200.

Henricksen, B., 2007. UNSDI Compendium: A UNSDI Vision, Implementation Strategy, and Reference Architecture. UNGIWG, pp. 150.

Heumesser, C., Fritz, S., Obersteiner, M., Pearlman, J., Khalsa, S.J.S., 2012. Benefits and challenges of voluntary contribution to GEOSS. Space Policy, 28: 244252.

Horsburgh, J.S. Tarboton, D.G., Piasecki, M., Maidment, D.R., Zaslavsky, I., Valentine, D., Whitenack, T., 2009. An integrated system for publishing environmental observations data. Environmental Modelling \& Software, 24: 879-888. 
Horsburgh, J.S., Jones, A.S., Stevens, D.K., Tarboton, D.G., Mesner, N.O., 2010. A sensor network for high frequency estimation of water quality constituent fluxes using surrogates. Environmental Modelling \& Software, 25: 1031-1044.

Horsburgh, J.S., Tarboton, D.G., Maidment, D.R., Zaslavsky, I., 2011. Components of an environmental observatory information system. Computers \& Geosciences, 37: 207-218.

Huang, M.T., Maidment, D.R., Tian, Y., 2011. Using SOA and RIAs for water data discovery and retrieval. Environmental Modelling \& Software, 26: 13091324.

Kao, S., Ranatunga, K., Squire, G., Pratt, A., Dee, D., 2011. Visualisation of hydrological observations in the water data transfer format. Environmental Modelling \& Software, 26: 1767-1769.

Kerr, Y. H., Waldteufel, P., Wigneron, J. P., Delwart, S., Cabot, F., Boutin, J., Escorihuela, M. J., Font J., Reul N., Gruhier C., Juglea, S. E., Drinkwater M. R., Hahne, A., Martin-Neira M. and Mecklenburg, S. (2010). The smos mission: New tool for monitoring key elements of the global water cycle. Proceedings of the IEEE 98: 666-687.

King, G., 2011. Ensuring the Data-Rich Future of the Social Sciences. Science 330: 719-721.

Lecca, G., Petitdidier, M., Hluchy, L., Ivanovic, M., Kussul, N., Ray, N., Thieron, V. 2011. Grid computing technology for hydrological applications. Journal of Hydrology 403: 186-199.

Lehmann, A., Giuliani, G., Mancuso, E., Abbaspour, K.C., Sözen, S., Gorgan, D., Beel, A., Ray, N., 2014. Filling the gap between Earth observation and policy 
making in the Black Sea catchment with enviroGRIDS. Environ. Sci. Policy, in press.

Leutbecher, M., Palmer, T.N. 2008. Ensemble forecasting. Journal of Computational Physics 227: 3515-3539.

Nativi, S., Mazzetti, P., Gary N.G., Environmental model access and interoperability: The GEO Model Web initiative, Environmental Modelling \& Software, Vol. 29, Jan 2013, pp. 214-228.

Nativi, S., Bigagli, L., 2009. Discovery, Mediation, and Access Services for Earth Observation Data. Ieee Journal of Selected Topics in Applied Earth Observations and Remote Sensing, 2: 233-240.

Nativi, S., Craglia, M., Pearlman, J., 2013, Earth Science Infrastructures Interoperability: The Brokering Approach, IEEE JSTARS, Vol. 6 N. 3, pp. 1118-1129.

Nebert, D.D., 2005. Developing Spatial Data Infrastructure: The SDI Cookbook, $171 \mathrm{pp}$.

Open Geospatial Consortium, 2004. The Havoc of Non-Interoperability, pp. 7.

Papajorgji, P., 2005. A plug and play approach for developing environmental models. Environmental Modelling \& Software, 20: 1353-1357.

Paudyal, D.R., McDougall, K., 2008. Buliding Spatial Data Infrastructure to support sustainable catchment management, Queensland Spatial Conference, Gold Coast, pp. 1-9.

Pebesma, E., Cornford, D., Dubois, G., Heuvelink, G.B.M., Hristopulos, D., Pilz, J., Stöhlker, U, Morin, G., Skøien, J.O., 2011. INTAMAP: The design and implementation of an interoperable automated interpolation web service. Computers \& Geosciences, 37: 343-352. 
Prandi, F., Amicis, R.D., Conti, G., Debiasi, A., 2012. Use of OGC web standard for a spatio-temporal enabled SDI for civil protection, Proceedings of the 17th International Conference on 3D Web Technology. ACM, Los Angeles, California, pp. 105-111.

Quevauviller Ph., 2002. Quality Assurance for Water Analysis, Water Quality Measurement Series, Volume 3, Quevauviller Ph. (Serie Editor), John Wiley \& Sons Ltd., Chichester, ISBN: 0-471-89962-3, pp. 252

Quevauviller Ph., Ed., 2010. Water Systems Science and Policy Interfacing, The Royal Society of Chemistry, Cambridge, ISBN: 978-1-84755-861-9, pp. 430

Quevauviller Ph., Borchers U., Gawlik B., 2007. Coordinating links among research, standardisation and policy in support of Water Framework Directive chemical monitoring requirements, J. Envir.Monitor., 9: 915-923.

Quinn, N.W.T., 2011. Adaptive implementation of information technology for real-time, basin-scale salinity management in the San Joaquin Basin, USA and Hunter River Basin, Australia. Agr Water Manage, 98: 930-940.

Rahman, K., Ray, N., Giuliani, G., Schwank, J., Giron, G., Escobar, R., George, C., Lehmann, A., Submitted. Breaking Walls Towards Fully Open Source Hydrological Modeling. Journal of Environmental Informatics.

Ray, N., Giuliani, G., Gorgan, D., Lehmann, A., 2012. Distributed Geocomputation for Modeling the Hydrology of the Black Sea Watershed. In: Lagutov, V. (Ed.), Environmental Security in Watersheds: The Sea of Azov. NATO Science for Peace and Security Series C: Environmental Security. Springer, pp. 141-157.

Roehring, J., 2002. Information Interoperability for River Basin Management, Technology Resource Management and Development, pp. 127-134. 
Rouholahnejad, E, Abbaspour, KC, Vejdani, M, Srinivasan, R, Schulin, R, Lehmann, A., 2012. A parallelization framework for calibration of hydrological models. Environmental Modelling \& Software, 31: 28-36.

Rouholahnejad E., K.C. Abbaspour, R. Srinivasan, V. Bacu, A. Lehmann. 2013a. A high resolution spatiotemporal distribution of water resources quantity and quality in the Black Sea Basin. Water Resources Research. Submitted.

Rouholahnejad E., Abbaspour K.C., Da Silva A.G., Mancosu E., Lehmann A. 2013b. Impact of changing climate and landuse on water resources of the Black Sea Basin. Climate Change. In preparation

Rummel, R., 2011. Goce - the gravity steady-state ocean circulation explorer preface. Journal of Geodesy, 85: 747-747.

Saarikivi, P., Söderman, D., Newman, H., 2000. Free information exchange and the future of European meteorology: a private sector perspective. Bull. Am. Meteorol. Soc. 81, 831-836.

Salzmann, M., 2011. Co-creating SDI's: bridging the gap between organizational cultures, FIG Working Week: Bridging the gap between organizational cultures, Marrakech, Morocco, pp. 10.

Signell, R.P., Carniel, S., Chiggiato, J., Janekovic, I., Pullen, J., Sherwood, C.R., 2008. Collaboration tools and techniques for large model datasets, Journal of Marine Systems, 69: 154-161.

Sun, X., Shen, S., Leptoukh, G., Wang, P., Di, L., Lu, M., 2012. Development of a Web-based visualization platform for climate research using Google Earth. Computers \& Geosciences, 47: 160-168.

Tarboton, D. G., Horsburgh, J. S., Maidment, D. R., Whiteaker, T., Zaslavsky, I., Piasecki, M., Goodall, J., Valentine D., Whitenack T., 2009. Development of 
a Community Hydrologic Information System. 18th World Imacs Congress and Modsim09 International Congress on Modelling and Simulation: 988994.

UN Global Pulse, 2012. Big Data for Development: Challenges \& Opportunities, New York.

UNEP, 2012. Global Environment Outlook (GEO) - 5: Environment for the future we want.

Vaccari, L., Craglia, M., Fugazza, C., Nativi, S., and Santoro, M., Integrative Research: The EuroGEOSS Experience, vol. 5, n. 6, IEEE ISTARS, April 2012, pp. 163-1611.

Viglione, A., Borga, M., Balabanis, P., Blöschl, G., 2010. Barriers to the exchange of hydrometeorological data in Europe: Results from a survey and implications for data policy. Journal of Hydrology, 394, 63-77. 


\section{Figure captions}

Figure 1. Selected projects and main international initiatives contributing to the development of water related spatial data infrastructures

Figure 2. Integrated hydrology between heterogeneous sources of data and end user needs.

Figure 3. Connecting data to end-users needs using SDI innovative solutions.

(ALL FIGURES IN COLOR ON THE WEB and GREYSCALE IN PRINTED VERSION) 

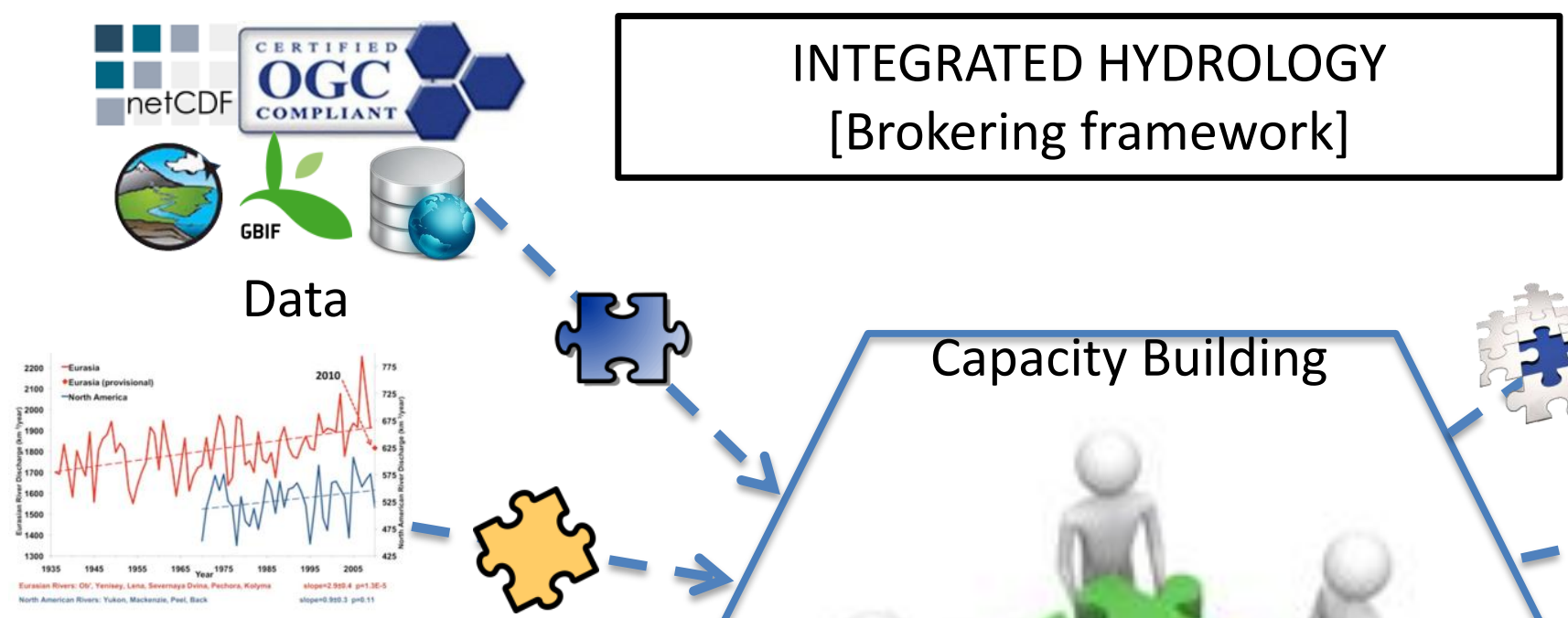

Temporal visualization

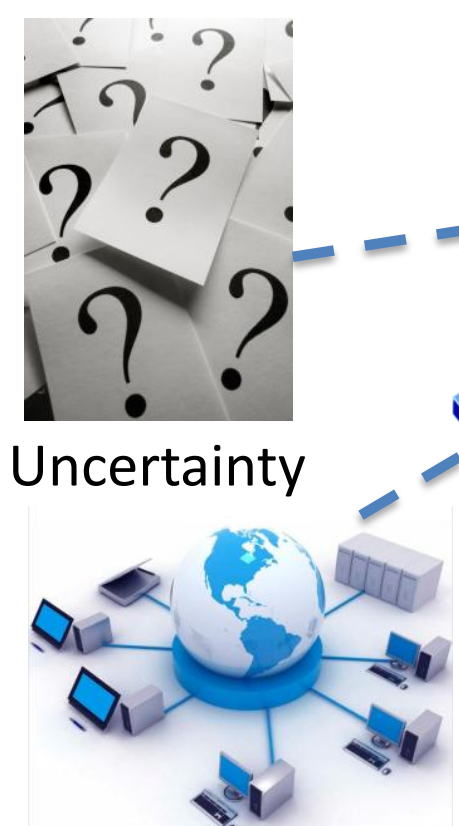

Distributed computing
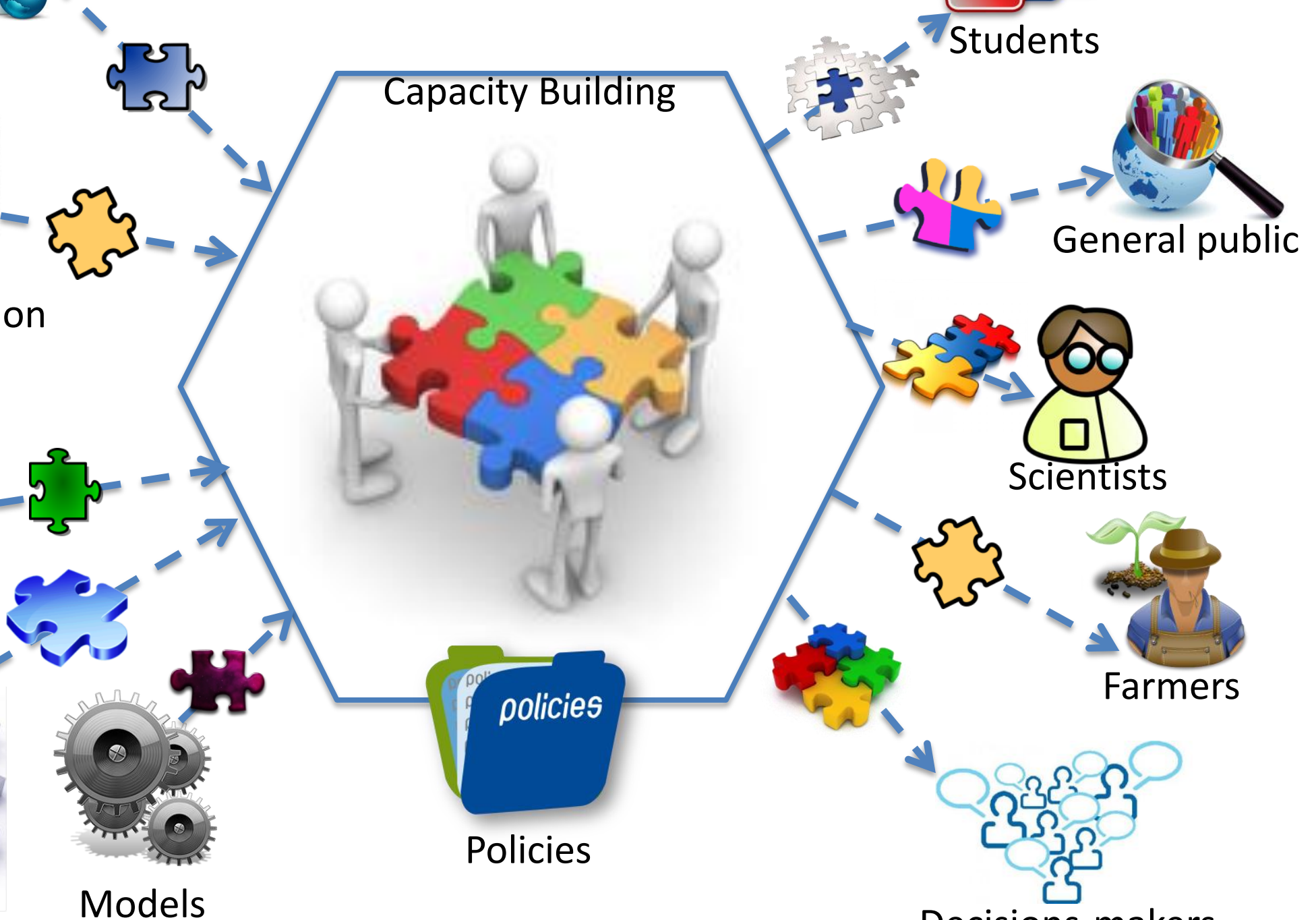

policies

Farmers

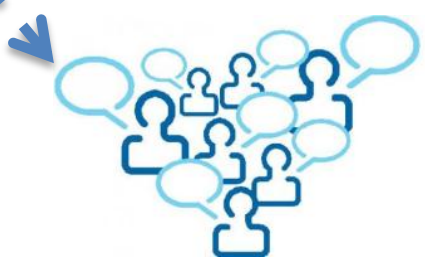

Decisions-makers
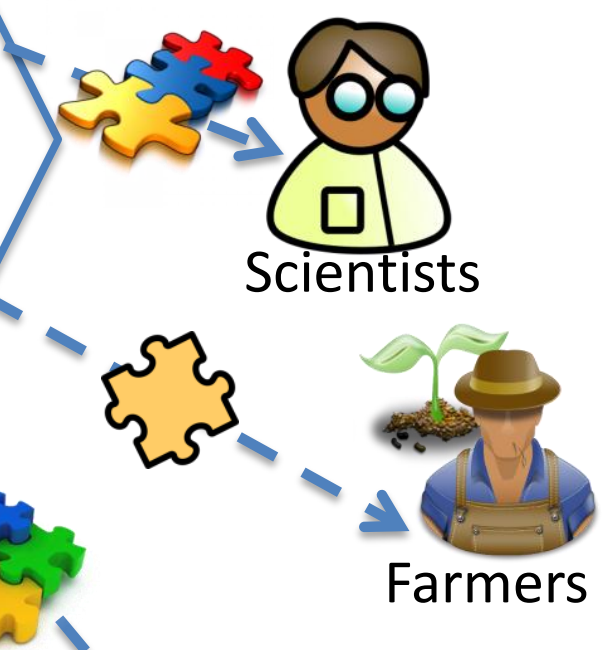

Policies

Models 


\section{DATA

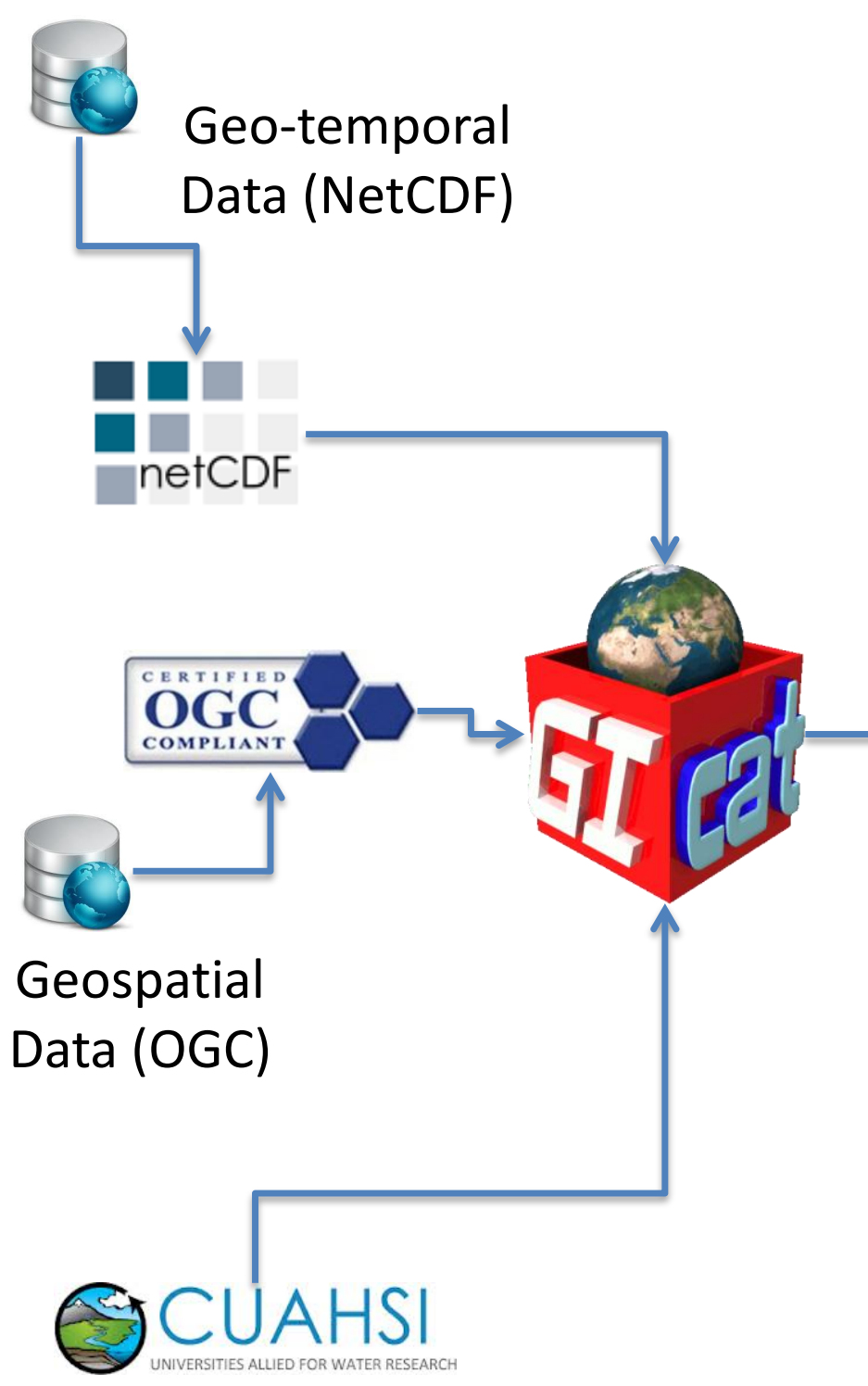

Real time Data

(WaterML, SensorML)
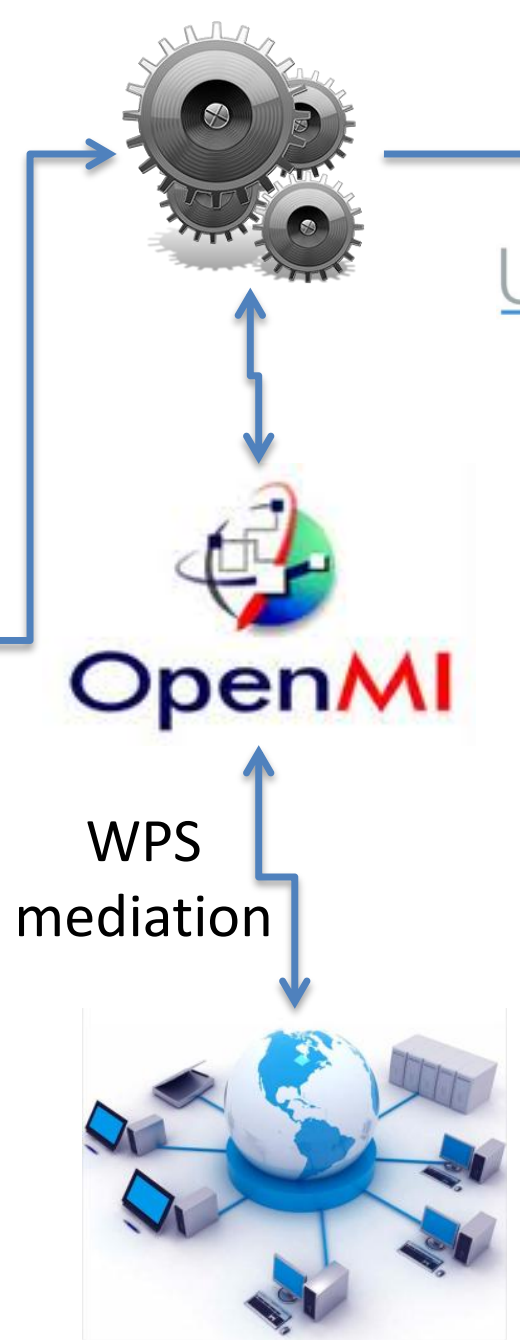

Distributed computing
BASYT DSS

Basin Scale Hydrologic Toolkit
General public

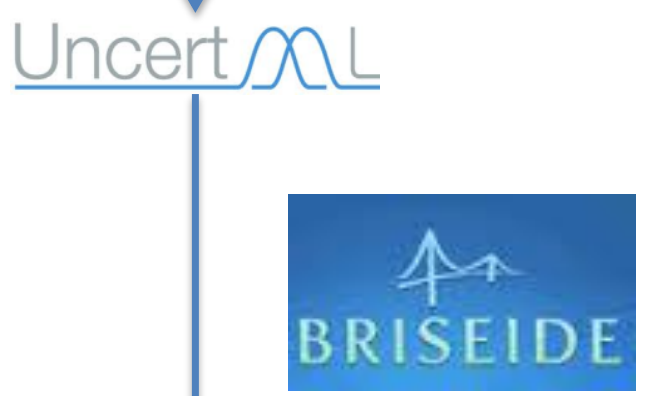

4D

Geoportals
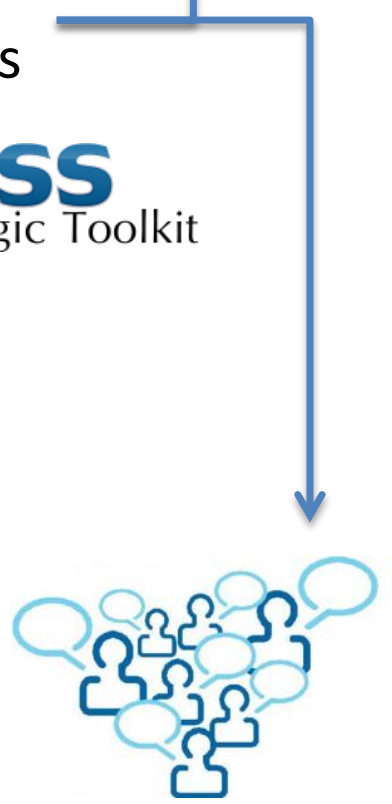

Decisions-makers 